Article

\title{
Submicron Particles during Macro- and Micro-Weldings Procedures in Industrial Indoor Environments and Health Implications for Welding Operators
}

\section{Pasquale Avino ${ }^{1, *}$, Maurizio Manigrasso ${ }^{1}$, Pietro Pandolfi ${ }^{2}$, Cosimo Tornese $^{2}$, Diego Settimi ${ }^{2}$ and Nicola Paolucci ${ }^{2}$}

1 DIT, INAIL Research Area, via IV Novembre 144, Rome I-00187, Italy; E-Mail: m.manigrasso@inail.it

2 Rheinmetall Italia S.p.A., Rome I-00100, Italy; E-Mails: pietropandolfi@ virgilio.it (P.P.); c.tornese@libero.it (C.T.); settimiposta@libero.it (D.S.); n.paolucci@ rheinmetall.it (N.P.)

* Author to whom correspondence should be addressed; E-Mail: p.avino@inail.it;

Tel.: +39-06-9789-2611; Fax: +39-06-9789-2590.

Academic Editor: Hugo F. Lopez

Received: 29 April 2015 / Accepted: 3 June 2015 / Published: 9 June 2015

\begin{abstract}
One of the emerging risks in the engineering and electronic industries is the exposure of workers to ultrafine particles during (micro-)welding operations, i.e., processes used for joining two metal parts heated locally, which constitute the base metal, with or without addition of another metal which is the filler metal, melted between the edges to be joined. The process is accompanied by formation of metallic fumes arising from the molten metal as well as by the emission of metal fumes of variable composition depending on the alloys welded and fused. The aim of this paper is to investigate the number, concentration and size distribution of submicron particles produced by (micro-)welding processes. Particle number size distribution is continuously measured during (micro-)welding operations by means of two instruments, i.e., Fast Mobility Particle Sizer and Nanoparticle Surface Area Monitor. The temporal variation of the particle number size distribution across the peaks evidences the strong and fast-evolving contribution of nucleation mode particles: peak values are maintained for less than $10 \mathrm{~s}$. The implication of such contribution on human health is linked to the high deposition efficiency of submicronic particles in the alveolar interstitial region of the human respiratory system, where gas exchange occurs.
\end{abstract}


Keywords: welding; micro-welding; submicron particles; indoor; occupational; FMPS; ultrafine particles; deposition; lobar; dose

\section{Introduction}

In the engineering industry, a large variety of manufactures from small metal objects up to large machines is produced. The production cycles of the engineering industries are generally very simple. They start from raw materials that may be metals in bars, rods or coils whereas the operations involve cutting machines, bending, drilling, pressing, grinding, turning operations, use of milling cutters and drills. Work centers vary for preparing the various parts to be welded or screwed or assembled.

Among the various risks associated with these processes (e.g., generic dust from grinding and/or sanding, polishing, calendering, nuisance dust in the case of epoxy coatings, respirable dust, crystalline silica, mists of mineral oils, solvent vapors) [1], fumes from welding pose a complex risk [2-7]. In these fumes, various components may be present both in gaseous phase and solid state (particles at different size, ultrafine particles_nanoparticles, inhalable dust, respirable dust) [8,9].

The welding, one of the most common procedures in such industries [10,11], is a process used to join two metal parts heated locally: this can occur with or without addition of another metal, which is the filler metal $[12,13]$, melted between the edges to be joined. The welding is heterogeneous when the molten filler material, which necessarily must have a lower melting point, shows a different composition from that of the pieces to be welded; this is the case of brazing in all its variants. Otherwise, the autogenous welding provides the fusion of the base metal (filler) which therefore must have a similar composition, or the fusion of only the edges to be welded pushed together by means of pressure (gas welding or electric arc) [14]. Brazing is carried out by placing the base metal so that, between the parts to be joined, there is a space both for allowing the filling of the joint and obtaining a connection for wetting and capillary action [15]. Depending on the lower or higher melting point of the filler metal, brazing stands in soft and hard. The soldering uses filler materials with melting temperature $<450{ }^{\circ} \mathrm{C}$; the filler materials are typical tin/lead alloys.

On the other hand, micro-welding is largely used in high-tech applications, especially for electronic devices [16,17]. The solder in electronics [18] has the main goal to ensure a good electrical connection between the parts to be welded [19-21]. It is also important and necessary to ensure a rigid mechanical, sturdy and long-lasting connection between the two metal surfaces. It is well to specify that the weld does not realize a simple 'bonding' but between the solder and the material it will form a thin transition layer consisting of an alloy composed of solder alloy and the material, the layer of which is called alloying. In fact, during the welding of $\mathrm{Cu}$ wire with $\mathrm{Sn}-\mathrm{Pb}$ alloy, a layer of $\mathrm{Cu}-\mathrm{Sn}-\mathrm{Pb}$ is formed: it ensures good mechanical and electrical connections [22]. If this layer is not formed, the welding is poor (cold welding) and both the electrical and mechanical connections are poor. Micro-welding is based on different technologies and equipment: these have the scope to be able to perform welding on thin or delicate materials. The welding processes are designed to maintain tight operational tolerances and to not interfere with product function and quality. Most of the micro-welding operations are carried out under microscope with suitable miniature tools to place exactly the hardware elements and filler metal (if 
present), and to control performance [23]. Devices where components are welded need that the equipment used for micro welding is able to locate the hardware itself with the required precision. The required amount of energy for welding is deposited in the exact spot. Although micro-welding, also called precision welding, is not a standard term identifying a specific process, and recognized as such by the AWS Terms and Definitions Committee, it is a loose description of any process applicable to thin or tiny joints for the purpose of establishing a permanent connection. Also, there is not yet universally accepted consensus on size. A common definition considers micro welds as all those having fusion zone dimensions less than $100 \mu \mathrm{m}$. Another definition would accept welds less than $0.5 \mathrm{~mm}$ wide as micro welds. Practically, any welding process suitable to be miniaturized in order to accomplish required diminutive welding could be included in the micro welding term. The following processes have been applied with success to micro-welding: resistance, flash, arc (TIG, MIG and plasma) and laser [24]. Also, electron beam welding could be considered for miniature welding. Applications include tiny medical implants, lamps and lighting assemblies, jewelry, dental appliances, aerospace items, hermetic sealing, batteries, thermocouples, wires, TV tube parts, sensing devices, electronic instrumentation, molds and tool build up and many other types of miniature work [25].

This paper shows the evaluation of number particle size distribution and relative surface area of submicron aerosol during (micro-)welding operations and, in particular, our attention has been focused on the particles in the nucleation mode $(5.6-16 \mathrm{~nm})$ : number concentration levels and behavior will be reported and debated according to the 'hard-welding' and 'soft-welding' investigated in this study. Further, a model describing the fate of such particles in the respiratory system in terms of deposition dose will be described: the evaluation of the deposited aerosol doses will be discussed in relationship with the particle diameter and the generations in the respiratory tract during welding operations. This information will be useful for understanding the risk of the workers exposed to welding (fumes) aerosol.

\section{Results and Discussion}

Real-time samplings were performed during repeated operations of $\mathrm{Sn}-\mathrm{Pb}$ micro-welding under suction. Figure 1a shows the trends of the temporal evolution of submicron particles $(5.6-560 \mathrm{~nm})$.

Firstly, it can be seen how the total number of particles produced is of the order of a million (over

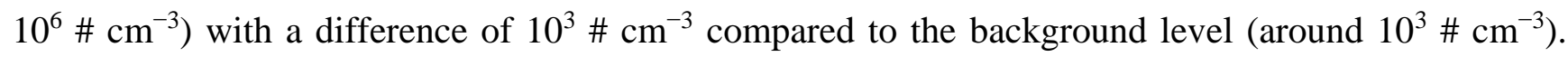
In detail, it is very interesting to note that particles in nucleation mode $(5.6-16 \mathrm{~nm})$ can be an important fraction: they are averagely $30 \%$ of the total fraction. Welding aerosols are initially formed from the nucleation of vapors emanating from the superheated metal droplets located within the arc, and from spatter particles ejected from the welding process [26]. The collision frequency of freshly nucleated particles with larger particles is high due to the Brownian diffusion enhanced by the high temperatures reached during welding, and to the high particle concentration. As a consequence, these particles are quickly formed and are removed to form larger particles, and aerosol size distributions quickly evolve with time. In case of repeated micro-weldings (basically, 8-10), when the dispersion of the particles is only limited by time factors, but permitted by a suction system, higher percentage ratios (up to $45 \%-50 \%$ of the total particles) are also reached. The micro-welding operation averagely produces 
$92000 \mathrm{\#} \mathrm{cm}^{-3}\left(\max 1.4 \times 10^{6} \mathrm{\#} \mathrm{cm}^{-3}\right)$ particles in contrast to the average number of particles produced during industrial welding operations (about $3 \times 10^{5} \mathrm{~m} \mathrm{~cm}^{-3}$, $\max 2 \times 10^{6} \mathrm{H} \mathrm{cm}^{-3}$ ) [27].

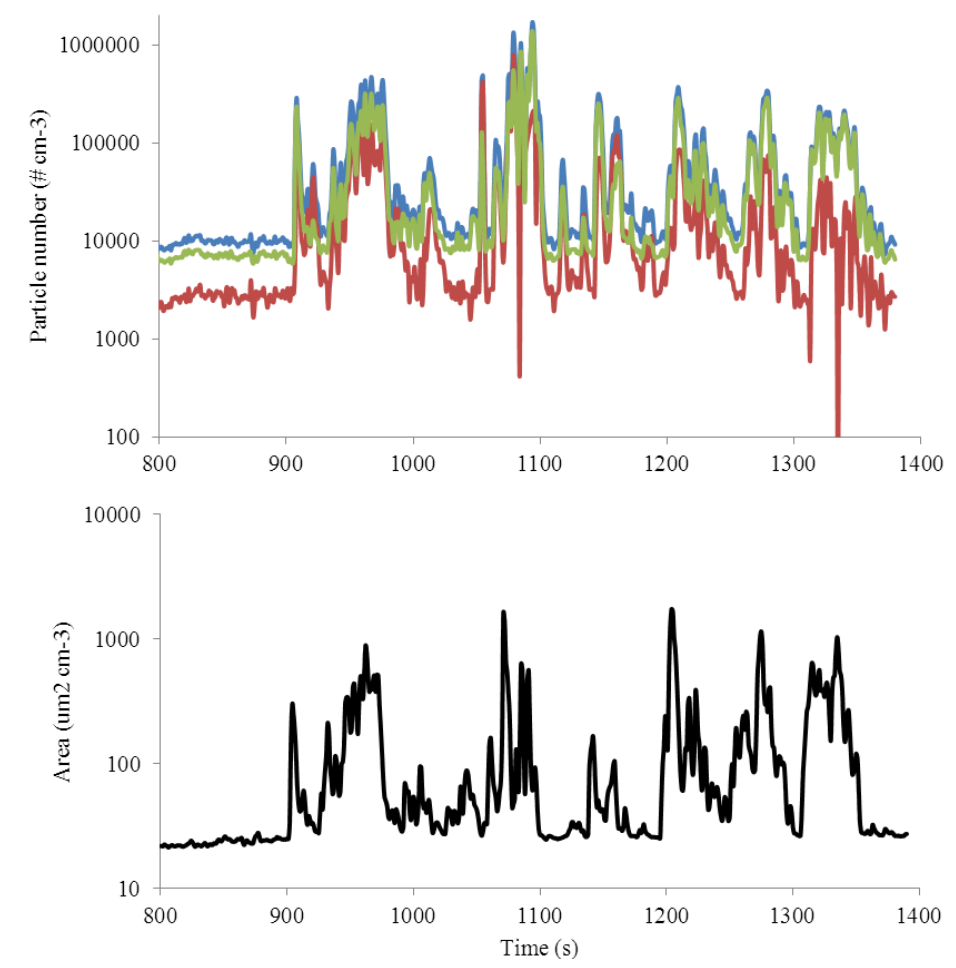

Figure 1. Performance of the three investigated modes $(6-560 \mathrm{~nm}$ blue line, $5.6-16 \mathrm{~nm}$ red line, 19-560 nm green line) (a) and the particle surface area (b) during the $\mathrm{Sn}-\mathrm{Pb}$ micro-welding operations.

Figure $1 \mathrm{~b}$ shows the simultaneous trend of the surface area of the particles during the same operation reported in Figure 1a: also in this case, there is a periodicity due to the repetition of the operation carried out. The measurement of the surface area is an important indication from the point of view of human health: the parameter thus becomes fundamental in the study of the depositions (total deposited alveolar surface area $0.012 \mathrm{~cm}^{2}$ ) along the respiratory tree with the relative doses. Stoeger et al. [28] showed that deposited surface area represents a valuable reference unit for the assessment of causative health effects for carbonaceous UFPs. Moreover, they demonstrated the existence of a threshold for the particle surface area at an instilled dose of approximately $20 \mathrm{~cm}^{2}$, below which no acute proinflammatory responses could be detected in mice.

Figure 2 a shows the behavior of the submicron particles during brazing operations. Such brazing operations are carried out in different environments than those where micro-welding operations previously analyzed are carried out: in this area, there are several sources of particles, external sources causing an elevated background level. 

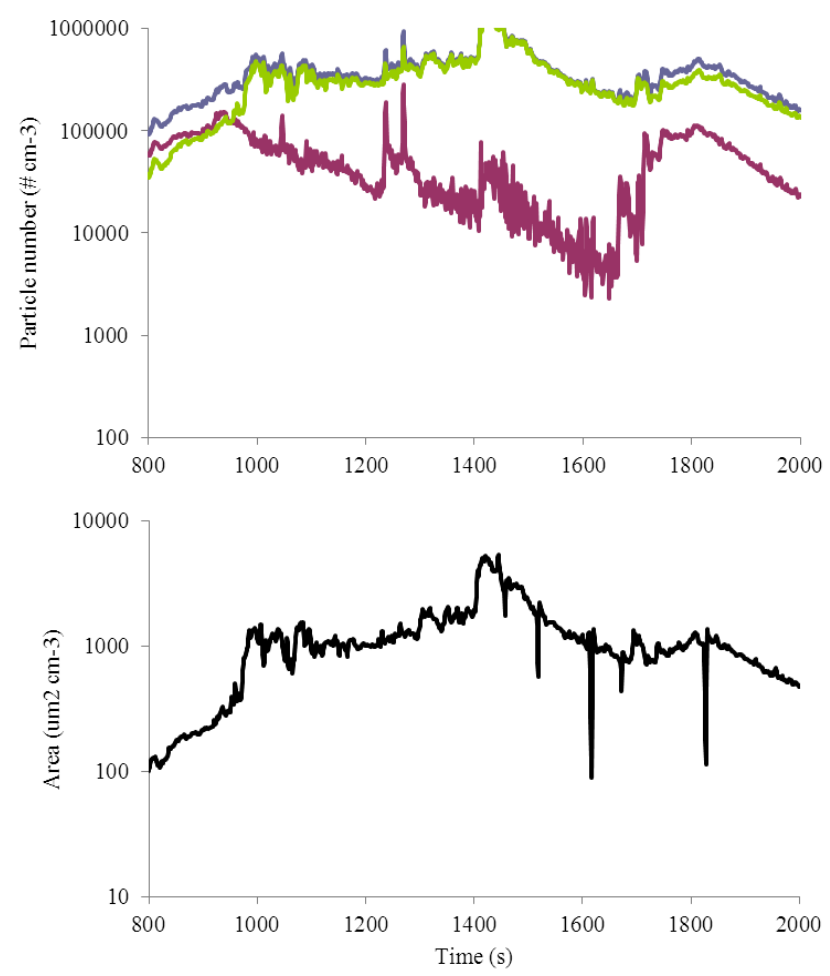

Figure 2. Performance of the three investigated modes $(5.6-560 \mathrm{~nm}$ blue line, $5.6-16 \mathrm{~nm}$ red line, 19-560 nm green line) (a) and the particle surface area (b) during the $\mathrm{Cu}-\mathrm{Al}$ soldering operations.

In such measures (Figure 2a), it can be noted how the background level is very high, around $1 \div 3 \times 10^{4} \mathrm{\#} \mathrm{cm}^{-3}$, whereas maximum particle peaks during similar operations are not so high. Moreover, particles in the nucleation mode exhibit different temporal trends: while the particles in the mode 5.6-16 nm decrease in number during the operations, and the particles in the mode $19-560 \mathrm{~nm}$ decrease, or at least remain constant, due to accumulation phenomena occurring in atmosphere. This can be explained by Figure 3 where particles in the nucleation mode are rapidly formed and are quickly removed by collision with accumulation mode particles.

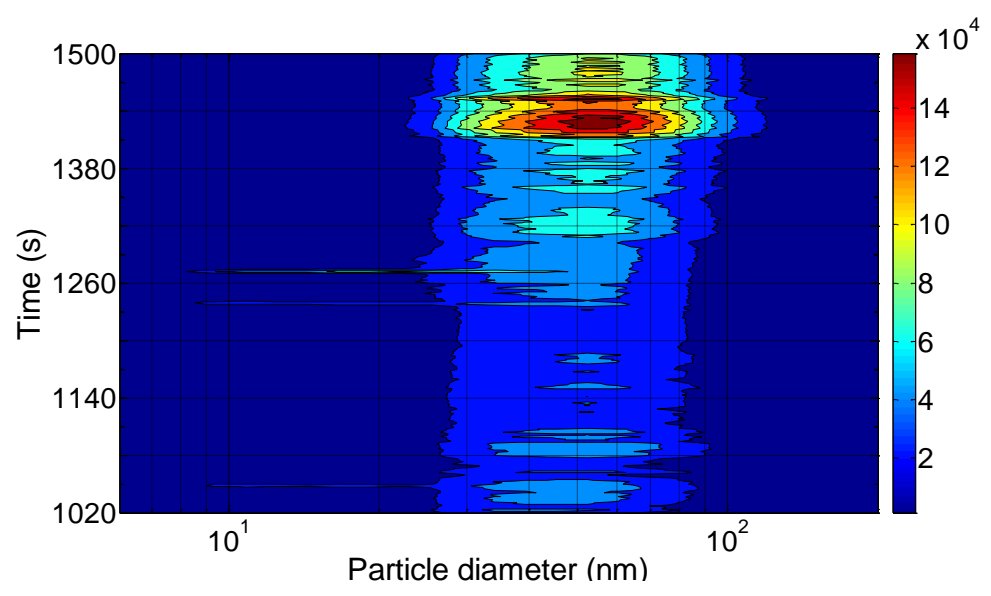

Figure 3. Temporal trend of aerosol size distribution $\left(\# \mathrm{~cm}^{-3}\right)$ during the $\mathrm{Cu}-\mathrm{Al}$ soldering. 
Figure $2 b$ shows the trend of the particle surface area: a very different behavior than previously studied (total deposited alveolar surface area $0.245 \mathrm{~cm}^{2}$ ) can be evidenced. In this case, the trend is continuously increasing, qualitatively very similar to the performance of the particles in the mode 19-560 $\mathrm{nm}$ with the exception of some peaks (negative) in correspondence with the operation change (further addition of borax on the sample to be brazed).

It is interesting to analyze the correlations between particles and surface area for the micro-welding and the brazing as well. Excellent correlation $\left(r^{2} 0.95\right)$ is noted between the number of particles in the mode 5.6-560 $\mathrm{nm}$ and the surface area during the brazing process, whereas this correlation is not good for the micro-weldings $\left(r^{2} 0.25\right)$ : this is probably due to the different surface action employed during brazing and so the measurements are statistically more correlated. Inside of the measures for a same process, however, the correlations between the total particles $(5.6-560 \mathrm{~nm})$ and those in the nucleation mode $(5.6-16 \mathrm{~nm})$ or those in the accumulation mode $(19-560 \mathrm{~nm})$ are good for the micro-weldings $(0.59$ per particles in the nucleation mode and 0.96 for the particles in the accumulation mode) whereas show values contrasting for brazing ( -0.29 for the particles in the nucleation mode and 0.99 for the particles in the accumulation mode).

Figure 4 shows the trend of total particles $(5.6-560 \mathrm{~nm})$ and particles in the mode $5.6-16 \mathrm{~nm}$ in the welding area during a typical MIG operation (electrode E 7018 ; heat input $0.43 \mathrm{~kJ} \mathrm{~mm}^{-1}$ ).

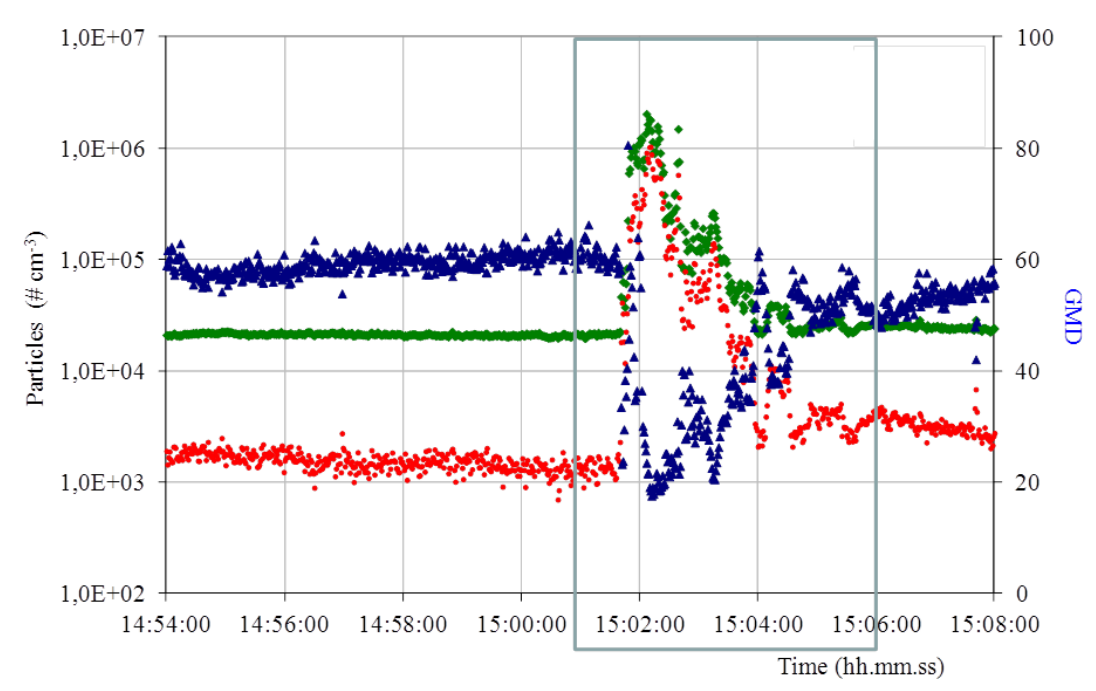

Figure 4. Submicronic particles (5.6-16 nm red circles; 5.6-560 green diamonds) and geometric mean diameter (blue triangles) during a Metal Inert Gas (MIG) welding.

The welding operation was carried out with suction whereas the sampling probe is positioned close to the respiratory system of the worker. This operation causes an instantaneous increase in the number of total particles and, in particular, ultrafine particles. Moreover, the considerations reported for Figure 1 as to nucleation mode particle can be easily seen in this figure where such particles steeply increase and become an important fraction of the total particle concentration (see box in Figure 4). In fact, the greatest increase is due to the particles with particle size 5.6-16 nm (about 3 orders of magnitude, up to $10^{6}$ particles $\mathrm{cm}^{-3}$ ), whereas the particles between 5.6 and $560 \mathrm{~nm}$ reach a maximum value over $2 \times 10^{6}$ particles $\mathrm{cm}^{-3}$. At the end of the welding operation, which lasted about $2 \mathrm{~min}$, the particles in the range $5.6-16 \mathrm{~nm}$ employ a latency time of about $3 \mathrm{~min}$ for returning to their plateau 
value around 25,000 particles $\mathrm{cm}^{-3}$. The proceeding of the welding particles in the size range $5.6-16 \mathrm{~nm}$ are greatly dispersed; this is due to the generation process in progress (welding) and the simultaneous removal, particularly efficient for these particles and due to their Brownian diffusion, and to the coagulation process after their collision with other particles. The particles in the mode 19-560 $\mathrm{nm}$ have, however, higher atmospheric residence times since both Brownian diffusion and the gravitational sedimentation are of poor efficiency for them.

After about $40 \mathrm{~s}$ from the start of welding, the particles in the nucleation mode increase from 7\%-60\%; simultaneously, geometric mean diameter (GMD) decreases from $60 \mathrm{~nm}$ to about $18 \mathrm{~nm}$. The highlighted part of this figure provides an attempted estimated of the doses that are deposited in the respiratory tract.

It should also be considered that the toxicity of welding fumes depends both on their chemical composition and the ability to penetrate and accumulate in the lungs. Their penetration and deposition in regions of the respiratory system is determined mainly by the size of the particles. An important part of this study is the estimation of the dose of aerosol deposited in function of the particle diameter and the generations of the respiratory system for a worker.

Ultrafine particles are extremely small when compared with the cellular structures and have a high surface area per unit mass [29-31]. They form aggregates and are easily deposited as aggregates in the lungs, where it can then disaggregate. About this, it should be noted that the measurements performed in this study show high concentrations of particles with numerical size less than $1 \mu \mathrm{m}$, in particular those in the nucleation mode. There are studies documenting the adverse effects of ultrafine particles [32-36] while current research is seeking to understand those mechanisms [37-39]. In any case, the high surface area of these particles seems to lead to phenomena of oxidative stress, and changes in calcium levels in macrophages and epithelial cells (promoting inflammatory mechanisms). For such particles, the surface area, rather than the mass, is the measure of the dose that best predicts the lung response, with important consequences for the occupational standards currently based on the particle mass [40,41].

The choice of the type of welding with respect to another one derives essentially from the type of welding: the particle production and their evolution are shown in detail in Figure 5, where in highlight it is also shown the size distribution of the particles in the range 5.6-560 nm at the maximum peak $\left(2 \times 10^{6} \mathrm{H} \mathrm{cm}^{-3}\right)$. In particular, from the analysis of the latter figure a bi-modal performance of the particles are evident with maximum peaks at $12 \mathrm{~nm}$ and $18 \mathrm{~nm}$ with values reaching $2.8 \times 10^{5} \# \mathrm{~cm}^{-3}$ for the mode at $12 \mathrm{~nm}$, whereas the particle number drastically decreases for particle sizes greater than $100 \mathrm{~nm}$.

The possibility to monitor this rapidly evolution, reported in Figure 6, is fundamental in the study of dose deposition in the human respiratory tract. In this case the use of FMPS is critical because it allows for a high temporal resolution [42]: in fact, the size aerosol distribution is measured every second (1 Hz).

The assessment of the doses was performed by the MPPD model: it calculates the deposition and clearance of aerosol mono- and poly-disperse, from ultrafine particles $(<100 \mathrm{~nm})$ to coarse mode particles in the human and rat respiratory systems; it considers the efficiency of particle deposition by diffusion, sedimentation and impact. 


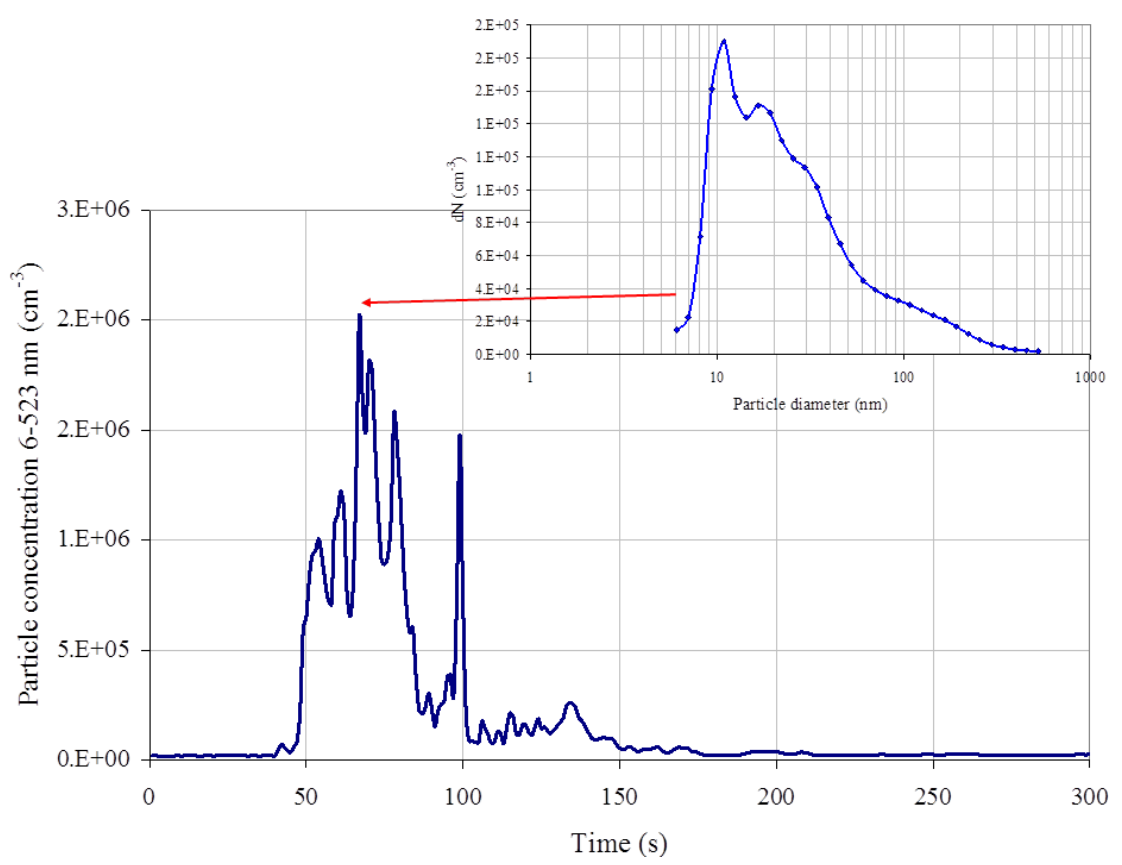

Figure 5. Evolution of the particle number concentration during an entire welding operation along with the highlight showing the particle number size distribution at the maximum particle generation peak.

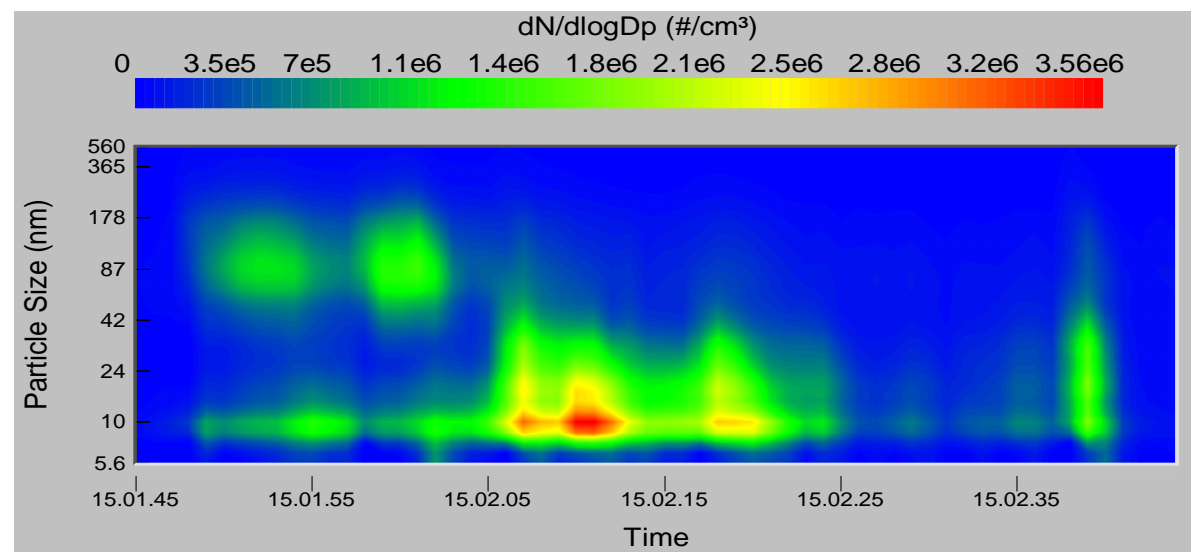

Figure 6. Dimensional distribution showing the rapid temporal evolution of particles during welding operations (Fast Mobility Particle Sizer software, release version 3.1.0.0, TSI, Shoreview, MN, USA).

In Table 1, the parameters of the model Multiple-Path Particle Dosimetry (MPPD) [43-45] used to evaluate the deposition of particles in the respiratory tract $[46,47]$ during the welding operation described in Figure 4 are reported.

Furthermore, the doses are calculated as a function both of the particle size and the generations of the respiratory apparatus (28 considering the trachea as generation 0 ). Such model includes single-path and multi-path methods for the calculation of the airflow and the aerosol deposition. On the other hand, the modeling of the human respiratory tract is based on an asymmetric stochastic model of the lungs: five symmetrical lobes (three lobes on the right side, two lobes on the left side) but each lobe is structurally different. 
Table 1. Multiple-Path Particle Dosimetry (MPPD) model parameters.

\begin{tabular}{cc}
\hline Stochastic Lung 60th Percentile & Data \\
\hline Functional Residual Capacity (FRC) & $3300 \mathrm{~mL}$ \\
Upper Respiratory Tract (URT) volume & $50 \mathrm{~mL}$ \\
Particle density & $3.7 \mathrm{~g} \mathrm{~cm}^{-3}$ \\
Breathing frequency & 20 per minute \\
Tidal volume & $1250 \mathrm{~mL}$ \\
Inspiratory fraction & 0.5 \\
Pause fraction & 0 \\
Breathing scenario & nasal \\
\hline
\end{tabular}

Figure 7 shows the deposition in the respiratory tract during the welding: $9.8 \times 10^{9}$ particles are deposited in the respiratory tract after approximately $80 \mathrm{~s}$ while the maximum deposition is at the $21 \mathrm{st}$ generation $\left(8.93 \times 10^{9}\right.$ particle after $\left.80 \mathrm{~s}\right)$.

Finally, Figure 8 shows the variations both of the dose deposited for each generation (red line) and the cumulative dose deposited (blue line) during a single welding process whereas the Figure 9 shows a contour plot where airway generation numbers are plotted vs. particle diameter. Analyzing both the graphs, it can be seen how the main contribution is due to the particles in the nucleation mode (maximum deposition for particles of $10.8 \mathrm{~nm}$ at the 20th generation, $D_{\max }, 1.36 \times 10^{7}$ particles) while it is estimated that the density of deposition is the maximum at lobar bronchi (third generation) for particles of $10.8 \mathrm{~nm}$ (the maximum deposition density calculated overall size class-generation number data pairs, $\tau_{\max }$, is $8.40 \times 10^{4}$ particles $\mathrm{cm}^{-2}$ ).

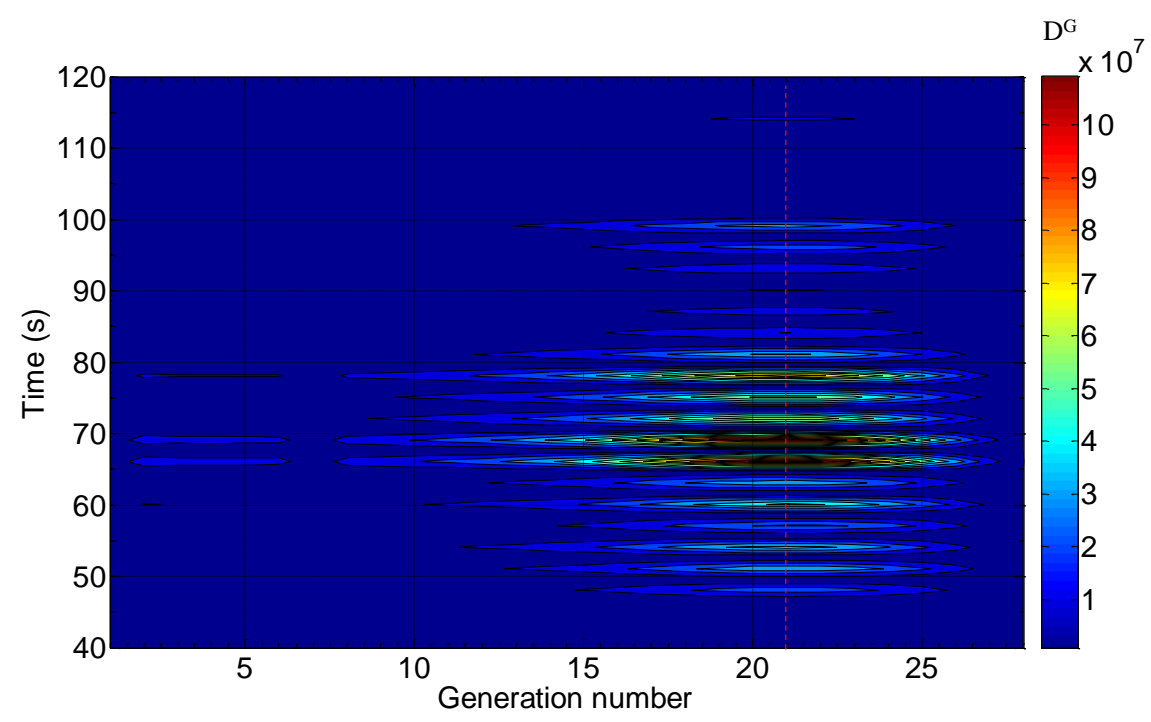

Figure 7. Contour plot showing the particle deposition for each generation number during a welding process: maximum deposition at the 21 st generation $8.93 \times 10^{9}$ particles $\left(D^{\mathrm{G}}\right.$ : total particle number dose deposited in the Gth generation). 


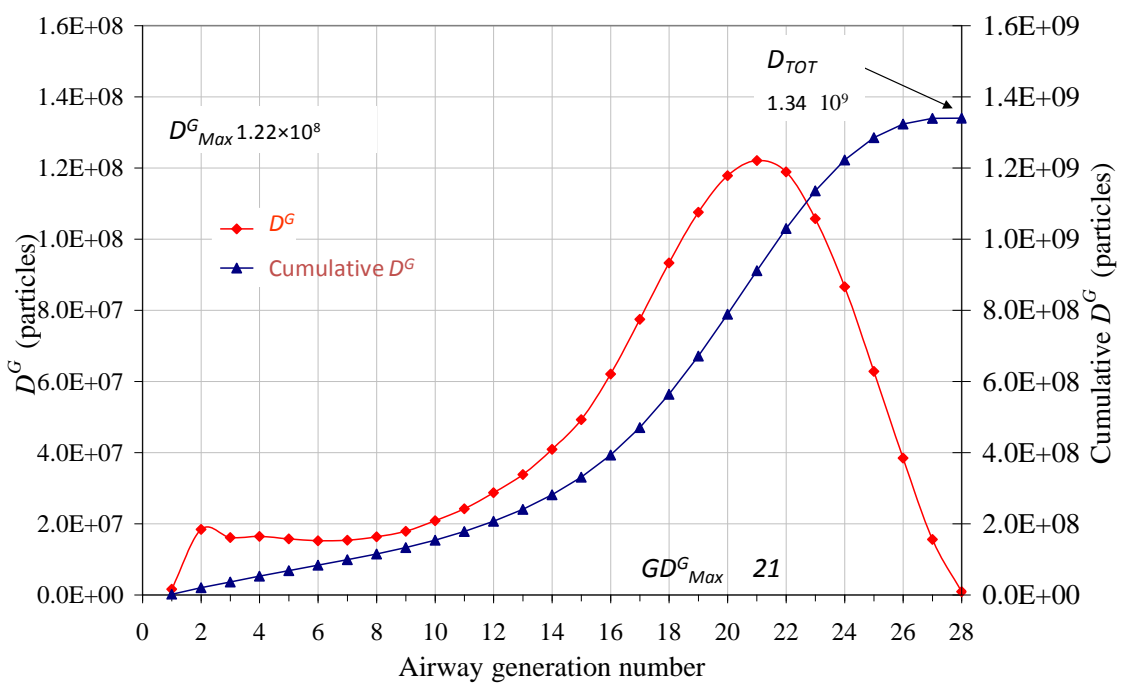

Figure 8. Dose deposited (red) for each generation and cumulative deposited dose (blue) during a single welding process $\left(D^{\mathrm{G}}\right.$ the total particle number dose deposited in the Gth generation; $D^{\mathrm{G}}{ }_{\max }$ the maximum dose per airway generation; $D_{\text {tot }}$ the total particle number dose deposited in the respiratory tree; $G D^{\mathrm{G}}$ max the airway generation number at $D^{\mathrm{G}}$ max).

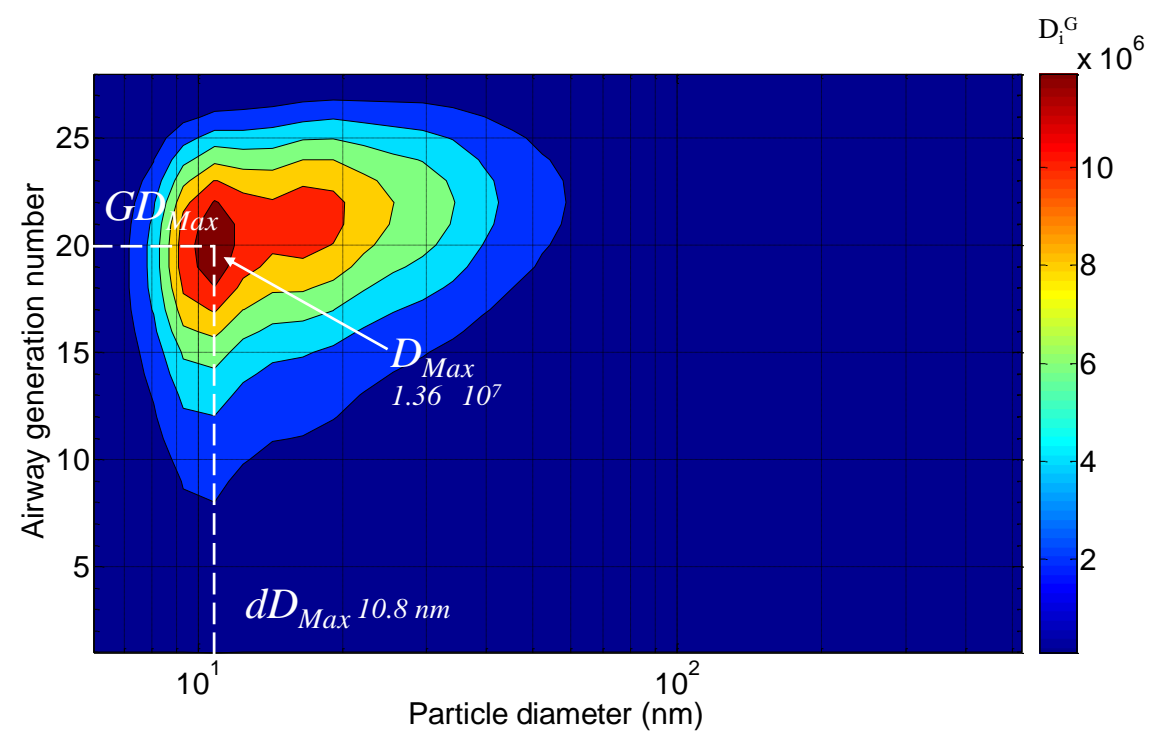

Figure 9. Contour plot reporting the airway generation number in relationship with the particle diameter $\left(D^{\mathrm{G}}{ }_{i}\right.$ the total particle number dose deposited in the $i$-generation; $G D^{\mathrm{G}}$ max the airway generation number at $D^{\mathrm{G}}$ max).

\section{Experimental Section}

\subsection{Materials and Methods}

This paper investigates the temporal evolution of submicron particles in the range 6-523 nm particle size (calculated as electric mobility diameter) and in particular the particle behavior in a size range $(5.6-16 \mathrm{~nm})$ that is representative of the nucleation mode. All the experimental measurements are started before the holding of the welding operations and are terminated after several minutes (between 10 and $20 \mathrm{~min}$, in general) so as to restore the background operating conditions of the acquisition system. 
The measurements were carried out both in the presence and absence of suction and ventilation devices. This measure has been used the Fast Mobility Particle Sizer TM Spectrometer (Model 3091 FMPS, TSI, Shoreview, MN, USA), a well-known instrument with high resolving size and time resolution, which allows collection, counting and provide the size distribution of particles with size from 5.6-560 nm [48,49]. Unlike the Scanning Mobility Particle Sizer (SMPS) [50,51] sampling takes place every second $[52,53]$.

This instrument charges the particles due to collision with an ionized gas; the particles thus charged are separated in function of their electrical mobility through flowing into a further electric field generated by electrometers. The instrument has 32 channels used for the separation of the particles. This tool, one of the most technologically advanced in the field of aerosol, allows to obtain the particle size distribution in the entire dimensional spectrum explored in a very short time (1 s). This occurrence allows to observe the ultrafine particles produced by combustion phenomena with respect to the particles formed by agglomerations of smaller particles (coagulation and/or gas-particle condensation), following simultaneously the kinetics of formation.

Over the FMPS instrument, a Nanoparticle Surface Area Monitor (Model 3550, TSI, Shoreview, MN, USA) was used for measuring the human lung deposited surface area of particles (expressed as $\mu \mathrm{m}^{2} \mathrm{~cm}^{-3}$ ) corresponding to tracheobronchial (TB) and alveolar (A) regions of the lung depending on the ion trap voltage [54]. The NSAM provides a simple and fast solution for detecting the surface area equivalent dose in the lung of particles in the size range of 10 to 1000 nanometers. The instrument is based on diffusion charging of sampled particles, followed by detection of the charged aerosol using an electrometer. The aerosol sample is drawn into the NSAM passing through a cyclone with $1 \mu \mathrm{m}$ cut point. The aerosol moves on to the electrometer for charge measurement. In the electrometer, current is passed from the particles to a conductive filter and measured by a very sensitive amplifier. The charge measured by the electrometer is directly proportional to the surface area of the particles passing through the electrometer. The ion trap voltages are optimized to correspond to the ICRP model-based tracheobronchial and alveolar lung deposition curves [55], and the NSAM indicates the lung deposited surface area, not the total active surface area of the aerosol sampled.

\subsection{Welding and Brazing Operations}

The measurements, repeated in several stages have been performed in different work processes: in the assembly, micro weldings of electronic circuits and/or connections have been carried while in the brazing area solderings were performed with brazing filler metal without melting the metal welding (Figure 10). The sampling probe was located on the worker's lapel.

In $\mathrm{Pb}$ and $\mathrm{Sn}$ micro-welding, the process took place under vacuum system (suction Weller WFE 2ES, Sparks, MS, USA; suction flow conveyed in a closed container with, in series, a pre-filter to reduce particulate and an activated carbon filter). The entire working operation of the micro-welding has occurred at the tip temperature of $320^{\circ} \mathrm{C}$ (with a peak of $380{ }^{\circ} \mathrm{C}$ ); the thread of $\mathrm{Sn} / \mathrm{Pb}$ (ratio 60/40) is of Sn section $0.5 \mathrm{~mm}$. During the soldering/desoldering operations, a solution of alcohol and chloroform was used as a fluxing. 


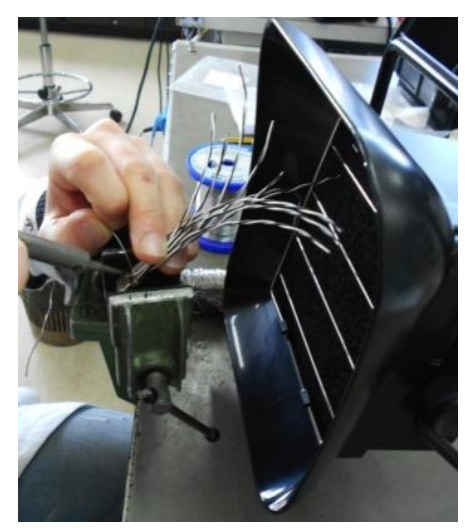

Figure 10. The micro-welding operation under suction (sampling probe was located on the worker's lapel).

After, the exposure was evaluated in the brazing process. The material to be welded is $\mathrm{Cu}$ or $\mathrm{Al}$, welded with filler material that is castolin (based-silver alloy) and alloy Al-Si, respectively. Aspiration is performed from the bottom (carbon filters, SAF-FRO Saldidactic Professional Welding Fumes Electrostatic Filtering System, Air Liquide Welding, Cergy-Pontoise, France); the temperature reached is of about $800{ }^{\circ} \mathrm{C}$. During the brazing operation borax is used. The welding torch is based on an oxy-acetylene flame. In this type of process (strongly dependent on the demand of the market), the operator is involved an average of 10 days per month with an average of $4 \mathrm{~h}$ per day.

\section{Conclusions}

The results of this study confirm that in the engineering industry and, particularly, during welding operations, there is significant production of submicronic (and ultrafine too) particles. Due to their size $(<100 \mathrm{~nm})$, they manage to reach the deeper portions of the respiratory system, spreading into the alveoli and reaching the bloodstream.

The analysis of the temporal distributions of particle size also highlights the following points:

$\checkmark$ very fast evolution of the particle size in the range of 5.6-560 $\mathrm{nm}$ during welding operations, in particular those in the nucleation mode;

$\checkmark$ importance of measures at high temporal resolution ( $1 \mathrm{~s}$ ) performed by FMPS for evaluating the particle size distributions during generation;

$\checkmark$ the total deposited alveolar surface area values are 20 -fold higher for $\mathrm{Cu}$-Al soldering than the $\mathrm{Sn}-\mathrm{Pb}$ micro-welding. To the authors' knowledge, studies correlating surface area to health effects have not been performed on metal fumes; nonetheless, the data obtained in this study represent a useful reference to interpret the health effects observed for welders;

$\checkmark$ due to their high particle deposition efficiency in the human respiratory system, such particles pose a (potential) risk to the human health associated with their high number, concentration and/or surface area. They should be the subject of further studies to continuously evaluate and monitor their effects. 


\section{Acknowledgments}

This research was performed under the grants INAIL/P20L01 and INAIL/P20L09.

\section{Author Contributions}

Pasquale Avino, Pietro Pandolfi and Nicola Paolucci are responsible for the research design. Pasquale Avino, Pietro Pandolfi, Cosimo Tornese and Diego Settimi conducted the field work. The paper was written by Pasquale Avino with significant contributions by Maurizio Manigrasso and Pietro Pandolfi. All the authors approved the paper.

\section{Conflicts of Interest}

The authors declare no conflict of interest.

\section{References}

1. Avino, P.; Manigrasso, M.; Carrai, P.; Rocchi, C.; Guerriero, E.; Russo, M.V. Ultrafine particles and chemical risk in automobile repair shops. Fresenius Environ. Bull. 2014, 23, 2956-2966.

2. Howe, A.M. Assessment of Exposure to Chemical Agents in Welding Fume: Final Report; HSL/2000/15, 2000. Available online: http://www.hse.gov.uk/research/hsl_pdf/2000/hs100-15.pdf (accessed on April 2015).

3. Riediger, G.; Möhlmann, C. Ultrafeine aerosole an arbeitsplätzen. Gefahrstoffe 2001, 61, 429-434.

4. Antonini, J.M. Health effects of welding. Crit. Rev. Toxicol. 2003, 33, 61-103.

5. Antonini, J.M.; Taylor, M.D.; Zimmer, A.T.; Roberts, J.R. Pulmonary responses to welding fumes: Role of metal constituents. J. Toxicol. Environ. Health Part A 2004, 67, 233-249.

6. Pires, I.; Quintino, L.; Miranda, R.M.; Gomes, J.F.P. Fume emissions during gas metal arc welding. Toxicol. Environ. Chem. 2006, 88, 385-394.

7. Gomes, J.F.P.; Albuquerque, P.C.S.; Miranda, R.M.M.; Vieira, M.T.F. Determination of airborne nanoparticles from welding operations. J. Toxicol. Environ. Health Part A 2012, 75, 747-755.

8. Maynard, A.D.; Zimmer, A.T. Evaluation of grinding aerosols in terms of alveolar dose: The significance of using mass, surface area and number metrics. Ann. Occup. Hyg. 2002, 46, 315-319.

9. Jenkins, N.T.; Eagar, T.W. Chemical analysis of welding fume particles. Weld. J. 2005, 84, 87s-93s.

10. Timings, R. Fabrication and Welding Engineering, 1st ed.; Elsevier: Oxford, UK, 2008; pp. 467-519.

11. Messler, R.W., Jr. Principles of Welding-Processes, Physics, Chemistry, and Metallurgy, 1st ed.; Wiley-VCH Verlag: Weinheim, Germany, 2004; pp. 3-40.

12. Kim, K.H. Welding Handbook Filler Materials for Manual and Automatic Welding, 5th ed.; Esab AB: Göteborg, Sweden, 1991; pp. 123-146.

13. O'Brien, R. Jefferson's Welding Encyclopedia, 18th ed.; American Welding Society: Miami, FL, USA, 1997; pp. 683-684.

14. Khan, I. Welding Science and Technology, 1st ed.; New Age International (P) Ltd.: New Delhi, India, 2007; pp. 37-68. 
15. Schwartz, M.M.; Aircraft, S. Introduction to brazing and soldering. In ASM Handbook-Welding, Brazing, and Soldering vol. 6, 9th ed.; Olson, D.L., Siewert, T.A., Liu, S., Edwards, G.R., Eds.; American Society for Metals International: Materials Park, OH, USA, 1983; pp. 270-481.

16. Zhou, Y. Microjoining and Nanojoining, 1st ed.; Woodhead Publishing Ltd., Woodhead Publishing: Cambridge, UK, 2008; pp. 1-810.

17. Fukumoto, S.; Tsubakino, H.; Zhou, Y. Resistance microwelding of fine nickel wires. In ASM Conference Proceedings: Joining of Advanced and Specialty Materials VII, Proceedings of the Conference on Materials Solutions 2004 on Joining of Advanced and Specialty Materials, Columbus, OH, USA, 18-20 October 2004; ASM International: Materials Park, OH, USA, 2005; pp. 168-173.

18. Pawlak, R.; Kostrubiec, F.; Tomczyk, M.; Walczak, M. Laser-induced change of electrical resistivity of metals and its applications. In Proceedings of SPIE-The International Society for Optical Engineering, Proceedings of the Conference on Lasers in Material Processing and Manufacturing II, Beijing, China, 10 November 2004; The International Society for Optical Engineering: Bellingham, WA, USA, 2005; Article number 55, pp. 349-360.

19. Fendrock, J.J.; Hong, L.M. Parallel-gap welding to very-thin metallization for high temperature microelectronic interconnects. IEEE Trans. Compon. Hybrids Manuf. Technol. 1990, 13, 376-382.

20. Steinmeier, D. Downsizing in the world of resistance welding. Weld. J. 1998, 77, 39-47.

21. Ely, K.J.; Zhou, Y. Microresistance spot welding of Kovar, steel, and nickel. Sci. Technol. Weld. Join. 2001, 6, 63-72.

22. Mo, B.; Guo, Z.; Li, Y.; Huang, Z.; Wang, G. Mechanism of resistance microwelding of insulated copper wire to phosphor bronze sheet. Mater. Trans. 2011, 52, 1252-1258.

23. Fukumoto, S.; Zhou, Y. Mechanism of resistance microwelding of crossed fine nickel wires. Metall. Mater. Trans. A Phys. Metall. Mater. Sci. 2004, 35, 3165-3176.

24. Ventrella, V.A.; Berretta, J.R.; de Rossi, W. Application of pulsed Nd: YAG laser in thin foil microwelding. Int. J. Mater. Product Technol. 2014, 48, 194-204.

25. Ely, K.J.; Hall, P.; Zhou, Y. Microwelding methods in medical components and devices. In Joining and Assembly of Medical Materials and Devices, 1st ed.; Zhou, Y.N., Breyen, M., Eds.; Woodhead Publishing Series in Biomaterials: Cambridge, UK, 2013; pp. 47-78.

26. Zimmer, A.T.; Biswas, P. Characterization of the aerosols resulting from arc welding processes. Aerosol Sci. 2001, 32, 993-1008.

27. Avino, P.; Manigrasso, M.; Fanizza, C.; Carrai, P.; Solfanelli, L. Particelle submicrometriche in fumi derivanti da operazioni di saldatura e di fusione di leghe metalliche. La Med. del Lav. 2013, 104, 335-350.

28. Stoeger, T.; Reinhard, C.;Takenaka, S.; Schroeppel, A.; Karg, E.; Ritter, B.; Heyder, J.; Schulz, H. Instillation of six different ultrafine carbon particles indicates a surface area threshold dose for acute lung inflammation in mice. Environ. Health Perspect. 2006, 114, 328-333.

29. Oberdörster, G. Pulmonary effects of inhaled ultrafine particles. Int. Arch. Occup. Environ. Health 2001, 74, 1-8.

30. Kreyling, W.; Semmler, M.; Mayer, P.; Takenaka, S.; Schulz, H.; Oberdörster, G.; Ziesenis, A.; Erbe, F. Translocation of ultrafine insoluble iridium particles from lung epithelium to extrapulmonary organs is size dependent but very low. J. Toxicol. Environ. Health Part A 2002, 65, 511-535. 
31. Avino, P.; Casciardi, S.; Fanizza, C.; Manigrasso, M. Deep investigation of ultrafine particles in urban air. Aerosol Air Qual. Res. 2011, 11, 654-663.

32. Pourtaghi, G.H.; Kakooei, H.; Salem, M.; Pourtaghi, F.; Lahmi, M.A. Pulmonary effects of occupational exposure to welding fumes. Aust. J. Basic Appl. Sci. 2009, 3, 3291-3296.

33. Fanizza, C.; Casciardi, S.; Avino, P.; Manigrasso, M. Measurements and characterization by Transmission Electron Microscopy of ultrafine particles in the urban air of Rome. Fresenius Environ. Bull. 2010, 19, 2026-2032.

34. Lehnert, M.; Pesch, B.; Lotz, A.; Pelzer, J.; Kendzia, B.; Gawrych, K.; Heinze, E.; van Gelder, R.; Punkenburg, E.; Weiss, T.; et al. Exposure to inhalable, respirable, and ultrafine particles in welding fume. Ann. Occup. Hyg. 2012, 56, 557-567.

35. Occupational Safety and Health (OSHA). Occupational Safety and Health Guideline for Welding Fumes. Available online: http://www.osha.gov/SLTC/healthguidelines/weldingfumes/ recognition.html. (accessed on March 2015).

36. Oberdörster, G.; Finkelstein, J.N.; Johnston, C.; Gelein, R.; Cox, C.; Baggs, R.; Elder, A.C. Acute pulmonary effects of ultrafine particles in rats and mice. Res. Rep. Health Eff. Inst. 2000, 96, 5-74.

37. Oberdörster, G. Toxicology of ultrafine particles: In vivo studies. Philos. Trans. R. Soc. B 2000, 358, 2719-2740.

38. Donaldson, K.; Stone, V.; Seaton, A.; MacNee, W. Ambient particle inhalation and the cardiovascular system: Potential mechanisms. Environ. Health Perspect. 2001, 109, 523-527.

39. Oberdörster, G.; Oberdörster, E.; Oberdörster, J. Nanotoxicology: An emerging discipline evolving from studies of ultrafine particles. Environ. Health Perspect. 2005, 113, 823-840.

40. Buonanno, G.; Morawska, L.; Stabile, L. Exposure to welding particle in automotive plants. J. Aerosol Sci. 2011, 42, 295- 304.

41. Gomes, J.; Albuquerque, P.; Miranda, R.; Santos, T.; Vieira, M. Comparison of deposited surface area of airborne ultrafine particles generated from two welding processes. Inhal. Toxicol. 2012, 24, 774-781.

42. Manigrasso, M.; Avino, P. Fast evolution of urban ultrafine particles: Implications for deposition doses in the human respiratory system. Atmos. Environ. 2012, 51, 116-123.

43. Manigrasso, M.; Stabile, L.; Avino, P.; Buonanno, G. Influence of measurement frequency on the evaluation of short-term dose of sub-micrometric particles during indoor and outdoor generation events. Atmos. Environ. 2013, 67, 130-142.

44. Manigrasso, M.; Buonanno, G.; Fuoco, F.C.; Stabile, L.; Avino, P. Aerosol deposition doses in the human respiratory tree of electronic cigarette smokers. Environ. Pollut. 2015, 196, 257-267.

45. Manigrasso, M.; Buonanno, G.; Stabile, L.; Morawska, L.; Avino, P. Particle doses in the pulmonary lobes of electronic and conventional cigarette users. Environ. Pollut. 2015, 202, 24-31.

46. Stabile, L.; Buonanno, G.; Avino, P.; Fuoco, F.C. Dimensional and chemical characterization of airborne particles in schools: respiratory effects in children. Aerosol Air Qual. Res. 2013, 13, 887-900.

47. Avino, P.; Lopez, F.; Manigrasso, M. Regional deposition of submicrometer aerosol in the human respiratory system determined at 1-s time resolution of particle size distribution measurements. Aerosol Air Qual. Res. 2013, 13, 1702-1711.

48. Manigrasso, M.; Avino, P.; Fanizza, C. Ultrafine particles in the urban area of Rome. Fresenius Environ. Bull. 2009, 18, 1341-1347. 
49. Buonanno, G.; Bernabei, M.; Avino, P.; Stabile, L. Occupational exposure to airborne particles and other pollutants in an aviation base. Environ. Pollut. 2012, 170, 78-87.

50. MacNee, W.; Li, X.Y.; Gilmour, S.; Donaldson, K. Systemic effects of PM10. Inhal. Toxicol. 2000, 12, 233-244.

51. Donaldson, K.; Stone, V.; Clouter, A.; Renwick, L.; Mac-Nee, W. Ultrafine particles. Occup. Environ. Med. 2001, 58, 211-216.

52. Buonanno, G.; Stabile, L.; Avino, P.; Vanoli, R. Dimensional and chemical characterization of particles at a downwind receptor site of a waste-to-energy plant. Waste Manag. 2010, 30, 1325-1333.

53. Buonanno, G.; Stabile, L.; Avino, P.; Belluso, E. Chemical, dimensional and morphological ultrafine particle characterization from a waste-to-energy plant. Waste Manag. 2011, 31, 2253-2262.

54. Marini, S.; Buonanno, G.; Stabile, L.; Avino, P. A benchmark for numerical scheme validation of airborne particle exposure in street canyons. Environ. Sci. Pollut. Res. 2015, 22, 2051-2063.

55. International Commission on Radiological Protection (ICRP). Human Respiratory Tract Model for Radiological Protection. International Commission on Radiological Protection (ICRP), Publication 66; Elsevier Science: Oxford, UK, 1994.

(C) 2015 by the authors; licensee MDPI, Basel, Switzerland. This article is an open access article distributed under the terms and conditions of the Creative Commons Attribution license (http://creativecommons.org/licenses/by/4.0/). 